\title{
3D public pipeline regulatory standards--a case study of Taiwan
}

\author{
Scarlet Liu ${ }^{a^{*}}$, Tony $\mathrm{Li}^{b}$ \\ ${ }^{a}$ Law School, Nankai University, Tianjin 300071, China \\ ${ }^{\mathrm{b}}$ National Kaohsiung University of Applied Sciences, Kaohsiung 80778, Taiwan \\ *Corresponding author: Scarlet Liu, PhD, ciumi09@gmail.com
}

\begin{abstract}
Complex underground pipeline makes it difficult for management. In recent years, along with the gradual implementation of various construction projects of the government, public underground pipeline are constantly changed and expanded. Most pipelines are buried layer by layer. However, currently they are presented in a 2D manner which is difficult to show their exact location and properly manage. This paper hopes to adopt 3D GIS, propose regulatory standards and provisions for 3D pipeline, set up 3D pipeline system with standard procedures and verification mechanism via project management and 3D geographic information technology. And it intends to establish effective pipeline safety management regulations so as to maintain life and property safety of the public.
\end{abstract}

Key words: 3D GIS, pipeline verification procedures, support mechanism, project management

\section{Introduction}

Since the establishment of "Standards and Policies for Public Facility Pipeline Database" by Land Resources Information System in 1998, Taiwan has started to promote national public facility pipeline database. Construction and Planning Agency, Ministry of the Interior cooperates the 10-year Plan of Land Resources Information System. Over the past decade, it had provided great support to the governments and units in various regions, and set up consistent "Common Specifications for Public Facility Pipeline Database Configuration" so that each agency can follow and implement it and ensure to obtain quality outcomes. Therefore, currently, more and more public facility pipeline databases as well as corresponding management and supply systems are being developed and launched. Gradually, consensus has been reached in terms of the promotion target. The system priority suggested by Common Specifications has been considered as an indicator by the governments at county and city levels ${ }^{1}$. 
The differences in the outcomes promoted by the governments at county and city levels lie in the facts that if system construction manufactures can fully understand their needs, and if the governments can understand relevant data standards, regulations, and controlling points of system supporting operations, summarize the characteristics of pipeline units, and design feasible promotion procedures and mechanisms based on policy directions and targets, in order to reach the final goals of promotion. If manufactures do not have the ability to verify system quality, the most pressure of system failure will be borne by the undertakers. Therefore, the professionalism of process planning is the key to the success policy and supporting system ${ }^{2-3}$.

\section{3D pipeline application requirement and function analysis}

Table 1 - Necessary functions of 3D pipeline geographic information system and the compliance of agencies

\begin{tabular}{|c|c|c|c|c|}
\hline No. & Necessary Functions & Taipei City & New Taipei City & Kaohsiung City \\
\hline 1 & Terrain indigitation (e.g. orthoimage, DEM) & Yes & Yes & Yes \\
\hline 2 & $\begin{array}{l}\text { Underground pipeline (transparent, see-through) } \\
\text { display }\end{array}$ & Yes & Yes & Yes \\
\hline 3 & 3D model indigitation & Yes & Yes & Yes \\
\hline 4 & Mass data display performance & Unknown & $\begin{array}{l}\text { Test of Banqiao } \\
\text { District }\end{array}$ & $\begin{array}{l}\text { Test with }>1.00 \text { million } \\
\text { entries of information }\end{array}$ \\
\hline 5 & Integration of 2D, 3D, and street view modes & No & Yes & No \\
\hline 6 & $\begin{array}{l}\text { Dual window, synchronization and asynchronous } \\
\text { mode }\end{array}$ & No & No & Yes \\
\hline 7 & Digging engineering, digging simulation mode & Yes & Yes & Yes \\
\hline 8 & Accident simulation (gas leak, explosion) & No & No & Yes \\
\hline 9 & Ring field display and pipeline data analysis & Only display & Yes & Yes \\
\hline 10 & Pipeline conflict analysis & No & No & Yes \\
\hline 11 & 3D graph-text inter-checking & Yes & Yes & Yes \\
\hline 12 & 3D data note & No & Yes & Yes \\
\hline 13 & Pipeline pixel floating and positioning display & No & Yes & No \\
\hline 14 & Pipeline pixel engineering mark & No & Yes & No \\
\hline 15 & Pipeline GML read & No & Yes & No \\
\hline 16 & Direct link to ArcGIS Server spatial database & Yes & Yes & Yes \\
\hline
\end{tabular}

Traditional 3D geographic information system is often positioned as simulation display. Coupled with terrain features and models, the existing terrain is presented via simulation. 
Hence, it is attractive to present slopes, plains, and cities with small scale and wide range. However, as 3D application requirements of pipeline data often must be shown with large scale and closely related to data quality (e.g. diameter and depth), there are few cases in domestic practice. And there are differences in target setting. Thus, this study, based on the application characteristics of pipeline data, put forward the necessary characteristics of demand, compare the current implementation progresses by agencies (At present, the agencies which promote pilot 3D public facility pipeline geographic information system include Taipei City, New Taipei City, and Kaohsiung City) to facilitate assessment and promotion ${ }^{4-5}$. See Table 1 for details.

\section{Pipeline standard regulations and integration planning}

\subsection{Source of geographic images and application planning}

This study collected information on public facility pipeline database and analyzed the basic image resources of 3D pipeline geographic system planning in Taichung City, as shown in Table 2.

In terms of the application of 3D public facility pipeline system, it will be key points to be considered in future design and implementation to match basic images under different scales with corresponding functions of pipelines, allow 3D pipeline system to meet engineering practice, and meet system implementation performance.

Table 2 - List of basic image resources of Taichung City

\begin{tabular}{|l|l|l|}
\hline No. & Name of Spatial Data & Units \\
\hline 1 & 1\%o numerical topographic map & Department of Urban Development \\
\hline 2 & Orthoimage & Department of Urban Development \\
\hline 3 & Administrative boundary images & Civil Affairs Bureau \\
\hline 4 & Road system images & Construction Bureau \\
\hline 5 & Building images & Department of Urban Development \\
\hline 6 & Images of important landmarks & $\begin{array}{l}\text { Research, Development } \\
\text { Evaluation Commission }\end{array}$ \\
\hline 7 & House number images & Civil Affairs Bureau \\
\hline 8 & 3D key building model & Information Center \\
\hline
\end{tabular}




\subsection{Analysis of problems of existing public facility pipeline data}

At present, the problem of 3D public facility pipeline construction lies in the drawbacks of 2D public facility pipeline databases. As 2D databases have insufficient basic data, 3D public facility pipeline cannot be presented normally. The visual strengths of 3D pipeline simulation are lost. The effectiveness to promote 3D pipeline is significantly reduced. Its reference significance is lowered. The degree of development of tools and their corresponding results are not satisfying ${ }^{6-10}$. Hence, it is a primary goal ${ }^{11-16}$ to face the current drawbacks of 2D data, design and promote programs based on the strengths of 3D tools, and solve data issues by years and periods. Therefore, this paper learns the influence caused by the current issues, and initially analyzes the current data issues and corresponding influences on 3D pipeline system, as shown in Table 3.

Table 3 - Current data problems and corresponding influences on 3D public facility pipeline system

\begin{tabular}{|c|c|c|c|}
\hline No. & $\begin{array}{l}\text { Current Problems of Existing Pipeline } \\
\text { Data }\end{array}$ & 3D System Presentation and Application Problems & $\begin{array}{l}\text { Degree of } \\
\text { Influence }\end{array}$ \\
\hline 1 & $\begin{array}{l}\text { Manhole cover, switch valve, and fixed } \\
\text { facility survey has the accuracy of } 20 \mathrm{~cm} \\
\text { of ground } x, y \text {, and } \mathrm{z} \text { measured values. }\end{array}$ & $\begin{array}{l}\text { Simulation presentation of the actual position can be } \\
\text { based on the measured values. }\end{array}$ & - \\
\hline 2 & $\begin{array}{l}\text { Data on the width, length, and caliber of } \\
\text { cover are missing. }\end{array}$ & $\begin{array}{l}\text { It fails to conduct simulation presentation based on } \\
\text { the actual values. } 3 \mathrm{D} \text { model presentation can serve } \\
\text { as reference, to some extent. }\end{array}$ & Medium \\
\hline 3 & The height of bottom of hole is missing. & $\begin{array}{l}\text { The bottom position of man-hand hole cannot be } \\
\text { calculated. It can only be presented with 3D model. }\end{array}$ & High \\
\hline 4 & $\begin{array}{l}\text { Data on measurement unit, diameter, } \\
\text { width, and height are missing. }\end{array}$ & $\begin{array}{l}\text { Pipeline type cannot be confirmed. And the actual } \\
\text { sectional position of pipeline cannot be calculated. It } \\
\text { can only be presented by the } 3 \mathrm{D} \text { model of default } \\
\text { value. }\end{array}$ & High \\
\hline 5 & $\begin{array}{l}\text { The minimum and maximum buried } \\
\text { depth values are missing. }\end{array}$ & $\begin{array}{l}\text { The underground location of pipeline cannot be } \\
\text { calculated. Pipeline will be laid above the ground, } \\
\text { exerting a serious impact on } 3 \mathrm{D} \text { pipeline fidelity. } \\
\text { And it brings about a great gap with terrain, which is } \\
\text { unacceptable. }\end{array}$ & High \\
\hline 6 & $\begin{array}{l}\text { The actual values of the lengths of poles } \\
\text { and other facilities are missing. }\end{array}$ & $\begin{array}{l}\text { It fails to conduct simulation presentation based on } \\
\text { the actual values. It can only be laid above the } \\
\text { ground. 3D model presentation can serve as } \\
\text { reference, to some extent. }\end{array}$ & Low \\
\hline
\end{tabular}


As mentioned above, through large-scale survey and construction plan, the completeness and correctness of the current 2D pipeline data still need to be improved. Due to the underground characteristics of pipeline, data problem really affects the correct presentation of 3D public pipeline data and system. Over the past few years, Construction and Planning Agency, Ministry of the Interior cooperated with the governments at county and city levels to control the source of new pipelines in pipeline excavation engineering, ensure data integrity and correctness, and render smooth follow-up 2D and 3D applications. The key controlling points of update and maintenance mechanism for new pipeline engineering drawing are described as follows ${ }^{17-22}$ :

\subsubsection{Accuracy of new and maintained pipelines (plane and elevation):}

(1) TWD97 or TWD97 (2010) secondary zoning system shall be adopted as plane coordinate system (The municipal government shall maintain and measure the coordinates based on the overall basic drawing). With respect to elevation coordinates, TWVD2001 elevation control system will be suitable.

(2) The allowable error of the measurement of the coordinates of hole cover center and fixed facilities is $20 \mathrm{~cm}$. The allowable error of the measurement of the linear coordinate of pipeline is $20 \mathrm{~cm}$. The allowable error of the measurement of the special lines along the turning parts of pipeline is $30 \mathrm{~cm}$.

(3) elevation measurement of hole cover elevation and turning points (and branch points) of pipeline shall be measured based on the wire points set up with the known controlling points in an indirect manner. The allowable error of the elevation measurement is $20 \mathrm{~cm}$.

A. Regulations on the operation control before, during, and after construction, as well as digital photo shooting (as the basis for information visual inspection):

a. During construction, digital photos of construction site shall be shoot (The photos shall include shooting time. Text and numbers shall be clearly displayed).

b. Digital photos shall clearly show the scope of construction. After pipeline is laid and before backfill, pay close attention to measurement marks and engineering conditions. Photos shall be classified into three major categories of those before construction (current situation), during construction (including traffic maintenance, road section, excavation equipment, excavation depth, pipe depth, and pipeline layout), and after construction (including backfill recovery, tamping equipment, and sampling countersignature).

B. Regulations on property data configuration of onsite pipeline survey and measurement: 
a. Coordinates, elevation, category code, identifier, man-hand hole (and facility) number, management unit, job distinction, depth of burying, and so on.

b. Pipeline: measurement unit, diameter, width, height, buried depths of the starting and end points, and so on.

c. Hole cover and fixed facilities: site height, hole depth, cover width, cover length, body diameter, depth of burying, and so on.

C. Regulations on the update and maintenance of images (operating methods, standard format conversion, and online update):

a. System-related function design: Verify data integrity.

b. Online update of SOP: Push pipeline units to operate according to standards

c. Incompliance with controlling measures: Punishment with scores deducted.

d. Submit data: Survey data and files, photos and description, and other supporting files.

To sum up, after the source control of the regulations on new pipeline engineering and maintenance and update of support mechanism, the next step is to face the issue of integrity and correctness of pipeline database of existing and buried pipelines. This is also a key point to be promoted by Construction and Planning Agency, Ministry of the Interior at the next stage. Hence, it is the challenge and key point of this study to propose suitable pipeline data update program and support mechanism, properly manage the characteristics of 3D pipeline geographic information system, and plan auxiliary operating standards ${ }^{23-26 .}$

\section{3D public pipeline data correction system and regulatory support mechanism planning} At present, counties and cities follow the policy direction proposed by Construction and Planning Agency to investigate the original data provided by pipeline units. The units that cannot provide property data or provide incomplete property data are listed. In light of the analysis of the common quality issues reflected in six major pipelines, the reliability of the key field property data of 3D pipeline is still low currently. It is necessary to plan rigorous and feasible support mechanism and raise 3D pipeline system to auxiliary analysis level for the application of subsequent pipeline units and approval units. The poor quality of current pipeline data shall be gradually improved. The initial planning is described as follows: 


\subsection{Promote data integrity, develop correction system for existing pipeline, and reinforce the correction of data by and control of pipeline units:}

(1) The system requires pipeline unit to correct by themselves. And it shall record the update of account authority. The results and progress of update of images by pipeline units shall be tracked monthly. The key points of design and regulation are described as follows:

a. Pipeline units update and correct images and conduct regular self-supervision.

b. Supervision and tracking by management units: Excellent pipeline units shall be rewarded as appropriate, while those getting slack shall be punished.

c. Establishment of close partnership among up, middle, and down streams: The supervised and tracked data shall be regularly reported to Construction and Planning Agency.

(2) In line with 3D system, a set of 3D pipeline correction and management system shall be created. 3D model shall support data correction.

(3) The existing pipeline data shall be verified. And conflicting modules shall be developed.

(4) The update and correction rates of images shall be checked by year and month. Statistics of rate of reaching the standard and difference value shall be conducted and displayed via figures.

(5) Two-stage correction model shall be designed. At the first stage, the missing properties shall be added. And doubtful spatial data shall be confirmed. Relevant pipeline data shall be extracted from exclusive image platforms. And each entry of data shall be reviewed. And corresponding properties shall be corrected. The system shall record correction and maintenance time and check integrity and logic rationality.

(6) At the second stage, in terms of doubtful spatial data, the pixel position of original configuration data shall be locked and unchanged. The doubtful parts shall be confirmed. And support mechanism shall be employed to correct follow-up data.

\subsection{Design of support mechanism for data correctness:}

In terms of doubtful data and setting of screening factors, through the conflict analysis and presentation of 3D pipeline system, data correctness shall be gradually corrected. The key points of the design of support mechanism are described as follows:

(1) Conflicting point first choice model shall be set up to gradually correct correctness.

(2) Design of screening factors for pipeline conflict analysis: The factors like pipeline basic images, import road sections (width), and intersections, shall be set. 3D pipeline conflict analysis shall be carried out for all pipeline images. 
(3) According to analysis result, the order of conflicting points shall be listed and provided to the competent department to hold follow-up coordination meeting on conflicting data of pipeline units and conduct data correction.

(4) The order of conflicting points can be analyzed based on the importance of factors. For instance, the quantity of conflicts between important road sections and pipeline types can be used for sorting.

(5) Demonstration area can be selected for pilot implementation to identify operating bottleneck, which is beneficial for the improvement of operating procedures and follow-up promotion of compliance by regions.

(6) Corrected conflicting data are feedback to pipeline data to serve as reference of indigitation of follow-up pipeline image update.

\section{Conclusions}

Over the years, Construction and Planning Agency of Taiwan allocates funds to the governments at county and city levels to construct pipeline data and system functions. However, the effects are limited. Moreover, the undertakers of units do not have specialty in IT. Pipeline management systems are still 2D. They fail to use information technology to improve data quality. Let alone they can have the chance to review the preciseness of engineering management regulations.

Laws and regulations are related to lives and property, even if such laws and regulations are on management. Take China for instance. In the past few years, frequent explosion of gas and wrong excavation occurred in Tianjin, Kunshan, and Qingdao. They are resolute to thorough solve the issues of pipeline. 3D pipeline is the most important method to manage pipeline. Through spatial calculation and analysis and data verification procedures, the correctness of pipeline data is improved. Therefore, it is a must to introduce new technology and engineering knowledge to set up more rigorous management regulations, better control engineering quality, reduce cost, and improve quality. More importantly, regulations and standards for public engineer shall be set up to secure the lives of people.

At present, Taiwan has begun to develop 3D pipeline management system and had fairly complete management procedures. The system mainly verifies and manages pipeline data, and plans the standard procedures for pipeline data configuration. Through scientific management, governmental units are expected to gradually clarify pipeline data and safeguard the safety of the public via more precise spatial analysis function. Although Kaohsiung 
experienced tragic gas exploration events, we shall turn crisis into opportunity. 3D pipeline system shall support the existing 2D pipeline system. Engineering management standards and regulations shall be set up. Coupled with efficient management procedures for analysis and verification, more rigorous 3D public pipeline regulations and most advanced pipeline management system can be developed.

\section{References}

1. Wen, J.L., 2004. The Influence of the Lifeline Manhole coverlid on Roughness of the Road, master's thesis, Graduate Institute of Civil Engineering, National Central University, Taoyuan.

2. Chen, P.Y., Lin, M.S., Sung, Y.M., Sung, H.J., 2005. Study on Pipeline Excavation Application Management System and Support Governmental Policies, 2005 Annual Meeting and Seminar of Taiwan Geographic Information Society, Taichung.

3. Public pipeline \& public facility pipeline website: http://w3.cpami.gov.tw/pw/web/index.html

4. Information Center, Ministry of the Interior. 2005. Report on the Results of Establishment of Standards and Policies Related to Data Circulation and Sharing Land Resources Information System, Taipei.

5. Information Center, Ministry of the Interior. 2006. Report on the Results of Establishment of Standards and Policies Related to Data Circulation and Sharing Land Resources Information System (2nd Year), Taipei.

6. Tsai, S.B., Wei, Y.M., Chen, K.Y., Xu, T., et al. 2016. Evaluating Green Suppliers from Green Environmental Perspective. Environment and Planning B-Planning \& Design, 2016, 43(5), 941-959.

7. Tsai, S.B. 2016. Using Grey Models for Forecasting China's Growth Trends in Renewable Energy Consumption. Clean Technologies and Environmental Policy, 2016, 18, 563-571.

8. Guo, J.J. and Tsai, S.B. 2015. Discussing and Evaluating Green Supply Chain Suppliers: A Case Study of the Printed Circuit Board Industry in China. South African Journal of Industrial Engineering, 2015, 26(2), 56-67.

9. Tsai, S.B., Huang, C.Y., Wang, C.K., Chen, Q., et al. 2016. Using a Mixed Model to Evaluate Job Satisfaction in High-Tech Industries. Plos One, 2016, 11(5): e0154071. doi:10.1371/journal.pone.0154071 
10. Lee, Y.C., Chu, W.H., Chen, Q., Tsai, S.B., et al. 2016. Integrating DEMATEL Model and Failure Mode and Effects Analysis to Determine the Priority in Solving Production Problems. Advances in Mechanical Engineering, 2016, 8(4), 1-12.

11. Tsai, S.B., Xue, Y., Zhang, J., Chen, Q., et al. 2016. Models for Forecasting Growth Trends in Renewable Energy. Renewable \& Sustainable Energy Reviews, 2016, DOI: 10.1016/j.rser.2016.06.001.

12. Qu, Q., Chen, K.Y., Wei, Y.M., et al. 2015. Using Hybrid Model to Evaluate Performance of Innovation and Technology Professionals in Marine Logistics Industry Mathematical Problems in Engineering, 2015, Article ID 361275, 8 pages, http://dx.doi.org/10.1155/2015/361275.

13. Zhou, J. Wang, Q., Tsai, S.B., et al. 2016. How to Evaluate the Job Satisfaction of Development Personnel. IEEE Transactions on Systems Man Cybernetics-Systems, 2016, 10.1109/TSMC.2016.2519860.

14. Su, J. M., Lee, S. C., Tsai, S. B. \& Lu, T. L. 2016. A comprehensive survey of the relationship between self-efficacy and performance for the governmental auditors. SpringerPlus, 2016, 5:508. DOI 10.1186/s40064-016-2104-x.

15. Tsai, S.B., Lee, Y.C. \& Guo, J.J. 2014. Using modified grey forecasting models to forecast the growth trends of green materials. Proceedings of the Institution of Mechanical Engineers, Part B: Journal of Engineering Manufacture, 2014, 228(6): 931-940.

16. Chen, H.M., Wu, C.H., Tsai, S.B., Yu, J., et al. 2016. Exploring key factors in online shopping with a hybrid model. SpringerPlus, 2016, 5:2046. DOI 10.1186/s40064-016-3746-4.

17. Deng, X.Y., Hu, Y., Deng Y. \& Mahadevan, S. 2014. Environmental impact assessment impact assessment based on numbers. Expert Systems with Applications, 2014, 41 (2), 635-643.

18. Wang, J., Yang, J., Chen Q. \& Tsai, S.B. 2016. Collaborative Production Structure of Knowledge-sharing Behavior in Internet Communities. Mobile Information Systems, Article ID 8269474, 9 pages, http://dx.doi.org/10.1155/2016/8269474.

19. Wang, J., Yang, J., Chen Q. \& Tsai, S.B. 2016. Creating the Sustainable Conditions for Knowledge Information Sharing in Virtual Community. SpringerPlus, 5:1019, DOI 10.1186/s40064-016-2702-7. 
20. Lee, Y.C., Wang, Y.C., Chien, C.H., Wu, C.H., et al. 2016. Applying Revised Gap Analysis Model in Measuring Hotel Service Quality, SpringerPlus, 5:1191, DOI 10.1186/s40064-016-2823-z.

21. Lee, Y.C., Wang, Y.C., Lu, S.C., Hsieh, Y.F., et al. 2016. An Empirical Research on Customer Satisfaction Study: A Consideration of Different Levels of Performance. SpringerPlus, 5:1577, DOI 10.1186/s40064-016-3208-z.

22. Chin, T., Tsai, S.B., Fang, K., Zhu, W., et al. 2016. EO-Performance relationships in Reverse Internationalization by Chinese Global Startup OEMs: Social Networks and Strategic Flexibility. PLoS ONE, 11(9): e0162175, doi:10.1371/journal.pone.0162175.

23. Lee, S.C., Su, J.M., Tsai, S.B., Lu, T.L., et al. 2016. A comprehensive survey of government auditors' self-efficacy and professional Development for improving audit quality. SpringerPlus, 5:1263, DOI 10.1186/s40064-016-2903-0.

24. Chen, H.M., Wu, C.H., Tsai, S.B., Yu, J., et al. 2016. Exploring key factors in online shopping with a hybrid model. Springer Plus, 5:2046, DOI 10.1186/s40064-016-3746-4.

25. Ge, B., Jiang, D., Gao, Y., \& Tsai, S.B. 2016. The Influence of Legitimacy on a Proactive Green Orientation and Green Performance: A Study Based on Transitional Economy Scenarios in China. Sustainability, 8, 1344, 1-20. doi:10.3390/su8121344.

26. Tsai. 2017. Using the DEMATEL model to explore the job satisfaction of research and development professionals in china's photovoltaic cell industry. Renewable \& Sustainable Energy Reviews, 2017, DOI: http://dx.doi.org/10.1016/j.rser.2017.07.014 